\title{
Correlation Between CRP Il-6 Level, Severity and Mortality in Patients with Covid-19 Infection in Indonesia
}

\author{
Inge Andriani, Arie Utariani*, Elizeus Hanindito \\ and Prananda Surya Airlangga
}

\author{
Anesthesiology and Intensive Care Department, Faculty of Medicine, \\ Universitas Airlangga, Surabaya 60286 Indonesia \\ *Corresponding author details: Arie Utariani; utarianiarie@gmail.com
}

\begin{abstract}
Background: IL-6 plays an important role in the occurrence of cytokine storm and is the major inducer of Creactive protein (CRP) gene expression in the liver. This study aims to analyze CRP and IL-6 levels as markers of severity and mortality in COVID-19 patients.

Methods: 50 subjects met the inclusion and exclusion criteria; the study was conducted using a retrospective observational cohort design and analyzed using Spearman-Rho and Mann Whitney test.

Results: There is relationship between CRP and the severity of COVID-19 with $p$ value $<0.001$ and $r$ value 0.604. The severity of IL- 6 and COVID-19 was also associated with a p-value of 0.017 and an R-value of 0.337 . CRP was also associated with mortality with a p value of 0.004 , where the baseline SOFA score was $p<0.001$ and the $r$ value was 0.551 . IL- 6 was associated with symptom onset with a p-value of 0.027 and an R-value of 0.314. Meanwhile, CRP and IL- 6 were associated with mechanical ventilation treatment with p-values of 0.013 and 0.027 , respectively. CRP also has a strong correlation with IL-6 levels with $p$ value $<0.001$ and $r$ value 0.557 .

Conclusion: Examination of CRP and IL-6 was associated with severity, complications and mortality in COVID19 patients, except that IL-6 was not associated with mortality because it is influenced by the patient's comorbid disease.
\end{abstract}

Keywords: COVID-19; CRP; IL-6; mortality; severity

\section{INTRODUCTION}

Coronavirus is a pathogen that attacks the human respiratory system. At the end of December 2019, in Wuhan, a number of patients were hospitalized with an initial diagnosis of pneumonia whose cause was still unknown. The patient was linked to a fish market in Wuhan, China. Then, on February 11, 2020, WHO determined that the cause of pneumonia cases in Wuhan was a new type of coronavirus, which was later named coronavirus disease (COVID-19), which was caused by severe acute respiratory syndrome coronavirus 2 (SARS-CoV2) (1).

There are $20.3 \%$ of COVID-19 patients who are known to require ICU care. $32.8 \%$ of patients had acute respiratory distress syndrome (ARDS), 13\% had acute cardiac injury (ACI), 7.9\% had acute renal failure, $6.2 \%$ had shock, and $13.9 \%$ died (2). Mortality from COVID-19 is related to cytokine storm as an immune response that is activated by the body and can also be related to the occurrence of fulminant myocarditis. Predictors of fatal outcome in COVID-19 include age, comorbid disease, secondary infection and elevated blood inflammatory indicators. Analysis of causes of death in COVID-19 of 68 fatal cases, $53 \%$ of deaths due to respiratory failure, $7 \%$ of deaths due to myocardial damage and circulatory failure, $33 \%$ of deaths due to both (3).

IL-6 plays an important role in the occurrence of cytokine storms. The initial stage of the infectious inflammatory phase is followed by the formation of IL- 6 by monocytes and macrophages, through stimulation by TLRs.
This acute IL-6 expression plays a central role in host defense by stimulating various types of cell populations. IL-6 can trigger the function and division of Th17 cells, inhibit the induction of regulatory $\mathrm{T}$ cells (Treg) where the function of Treg is to produce anti-inflammatory cytokines, and vice versa in Th17, and trigger the formation of a selfreactive pro-inflammatory $\mathrm{CD} 4 \mathrm{~T}$ cell response. Effects on hepatocytes, IL-6 is a potent trigger of acute phase reactive protein, which can trigger hepatocytes to synthesize acute phase reactive proteins at the gene transcription level, especially serum amyloid A (SAA) and C-reactive protein (CRP) (4).

CRP is a homopentameric acute-phase inflammatory protein, belonging to the pentraxin family. Induction of transcription of the CRP gene mainly occurs in hepatocytes in the liver in response to an increase in inflammatory cytokines, especially IL-6. The main role of CRP is the activation of the $\mathrm{C} 1 \mathrm{q}$ molecule in the complement pathway causing opsonization of pathogens, also plays a role in apoptosis, phagocytosis and cytokine production. CRP levels are elevated in infectious and inflammatory conditions, especially in bacterial infections (5).

IL- 6 and CRP can be used as independent factors to predict disease progression in COVID-19, where 140 patients used procalcitonin (PCT) as a predictor of disease risk. The study said that IL-6 levels of more than $32.1 \mathrm{pg} / \mathrm{mL}$ or CRP levels of more than $41.8 \mathrm{mg} / \mathrm{L}$ indicated severe complications and increased levels of IL- 6 or CRP were 
significantly seen in the seriously ill group compared to the sick group light (6).

Data from the World Health Organization (WHO) regarding COVID-19, as of October 6, 2020 worldwide there were $26,763,217$ confirmed cases of COVID-19 with a death toll of 876,616 people. In Indonesia alone there are 194,109 confirmed cases of COVID-19, with the number of patients who died as many as 8025 people based on the official website of the Task Force for the Acceleration of Handling COVID-19. The high mortality rate mainly occurs in severe and critical cases

The magnitude of the role of IL- 6 in causing cytokine storm is related to the severity and death and synthesis of CRP by hepatocytes induced by IL- 6 induction, so that CRP and IL-6 should be good predictors of severity, mortality and the need for mechanical ventilation. in this case as proven in several previous studies, but IL-6 is not a routine examination in Indonesia while CRP is a routine examination that is easy and inexpensive. There is another study which states the opposite that in COVID-19 patients IL-6 levels generally never exceed $30 \mathrm{pg} / \mathrm{mL}$ (7). For this reason, this study was prepared with the aim of analyzing CRP and IL-6 levels as markers of severity and mortality in patients with COVID-19 infection at the time of initial admission, which occurred in Indonesia.

\section{METHOD}

The method used in this study is an observational analytic study with a retrospective cohort design. While the study population is all COVID-19 patients who are treated in the Special Isolation Room of RSUD Dr. Soetomo Surabaya, Indonesia, with reference to research samples taken from the population with several inclusion and exclusion criteria from medical records from July to October 2020. It was found that there were 54 patients who met the inclusion and exclusion criteria. However, 4 patients dropped out due to sample errors and incomplete initial data, so this study involved 50 patients. The inclusion criteria in this study were adult patients (aged 19 years), patients with clinical symptoms of COVID-19 and positive COVID-19 confirmed by RT-PCR results from nasopharyngeal swabs 2 times, willing to participate in the study, and receiving treatment according to standards protocol. While the exclusion criteria in this study were patients with HIV or other immunocompromised disease, patients with a history of autoimmune disease or receiving immunosuppressant therapy, patients with malignancy, patients with a history of taking anti-IL-6, surgical or perioperative patients, patients who were pregnant, or is in the puerperium.

The research started in July 2020 until June 2021. Thus, this research was carried out for approximately one year. The location of the research was carried out in the COVID19 special treatment room at Dr. Soetomo Surabaya, Indonesia, and the Clinical Pathology and Microbiology Laboratory of Dr. Soetomo Surabaya, Indonesia.

\section{RESULT}

A total of 54 people met the inclusion and exclusion criteria in this study, where there were 4 patients who dropped out due to incomplete initial data and sample lysis, so that the remaining 50 subjects in the study could be included in this study until the study was completed. In general, the subjects of this study have some of characteristics.

The patient's age was in the median range of 51(25 - 76) years, with a mean \pm SD of $49.80 \pm 11.899$. Based on gender, there were 34 male patients (68\%) and 16 female patients (32\%).

BMI was in the median (range)24.97(20.44 - 48.07) $\mathrm{kg} / \mathrm{m} 2$, with a mean \pm SD $26.685 \pm 5.536$. In the BMI category there are 26 people with a BMI in the normal category of $18.5-24.9 \mathrm{~kg} / \mathrm{m} 2$ (52\%), overweight category 16 people $25-29.9 \mathrm{~kg} / \mathrm{m} 2$ (32\%), and obesity category 8 people $30 \mathrm{~kg} / \mathrm{m} 2$ (16\%).

SOFA scores at the time of admission were in the median (range) $3.5(0-8)$, with a mean \pm SD of $3.24 \pm 1.93$. Onset of symptoms occurred in the range of 1 day to 15 days with a mean \pm SD $7.4 \pm 3.75$. Deterioration during treatment occurred in 33 patients $(66 \%)$ and the remaining 17 patients (34\%) experienced improvement during treatment (8).

There were 37 patients with comorbidities (74\%) and 13 patients without comorbidities (26\%). There were 9 types of comorbid disease in the subjects of this study and some patients had comorbid more than 1 type of comorbid disease. There were 17 patients with hypertension (34\%), Diabetes Mellitus 14 patients (28\%), Obesity 8 patients (16\%), Asthma and coronary heart disease there were 2 patients each (4\%), the rest were COPD, CVA, Hepatitis B chronic and reactive HBsAG in 1 patient $(2 \%)$. There was a secondary infection in 20 patients $(40 \%)$ while the other 30 people $(60 \%)$ did not have a secondary infection.

The onset of symptoms had a median (range) of $7(1-15)$ days with a mean \pm SD of $7.4 \pm 3.75$. The length of treatment in the median (range) was $18(2-69)$ days, with a mean \pm SD of $20.7 \pm 14.01$. The number of patients who died was 15 patients $(30 \%)$, while 35 patients were alive $(70 \%)$.

The results of the CRP examination in this study had a median (range) of $5.65(0.10-28.80) \mathrm{mg} / \mathrm{dl}$, with a mean $\pm \mathrm{SD}$ of $8.76 \pm 8.029$. IL-6 examination had a median (range) of $46,712(0.24-3029.17) \mathrm{pg} / \mathrm{ml}$, with a mean \pm SD of $219,788 \pm 551,744$.

The most common clinical symptoms experienced were fever in 37 patients (74\%), shortness of breath in 37 patients $(74 \%)$, dry cough in 33 patients $(66 \%)$, followed by colds in 10 patients (20\%), nausea, and vomiting in 9 patients (18\%), decreased appetite in 8 patients (16\%), anosmia and cough with phlegm in 6 patients $(12 \%)$, diarrhea and sore throat in 5 patients $(10 \%)$, others clinical symptoms were fatigue, pain Abdominal, myalgia, chest pain, headache, loss of sense of taste, decreased consciousness and hemiparesis all were less than $10 \%$.

TABLE 1: Analysis of the Relationship between CRP and the Severity of COVID-19*

\begin{tabular}{|c|c|c|c|c|c|}
\hline Severity & N (\%) & $\begin{array}{c}\text { Median (Range) } \\
\text { (mg/d) }\end{array}$ & Mean \pm SD & p & r \\
\cline { 1 - 4 } Mild & $6(12 \%)$ & $1,1(0,3-5,6)$ & $1,85 \pm 1,981$ & & \\
\cline { 1 - 4 } Moderate & $6(12 \%)$ & $2,6(0,1-11,5)$ & $3,783 \pm 4,348$ & \multirow{2}{*}{0,001} & 0,604 \\
\cline { 1 - 4 } Severe & $25(50 \%)$ & $5,5(1,3-26,3)$ & $8,056 \pm 6,793$ & & \\
\cline { 1 - 5 } Critical & $13(26 \%)$ & $15,8(2,1-28,8)$ & $15,80 \pm 8,572$ & & \\
\hline
\end{tabular}

${ }^{*}$ COVID-19 severity categorized according to the severity of the China National Health Commission. 
The results of the examination of mild CRP levels have a median (range) of $1.1(0.3-5.6) \mathrm{mg} / \mathrm{dl}$ with a mean $\pm \mathrm{SD}$ of $1.85 \pm 1.981$, moderate degrees of $2.6(0.1-11.5) \mathrm{mg} / \mathrm{dl}$ with mean \pm SD $405,950 \pm 878,805$, severity $5.5(1.3-26.3)$ $\mathrm{mg} / \mathrm{dl}$ with mean \pm SD $8056 \pm 6.793$, critical severity
$15.8(2.1$ - 28.8) $\mathrm{mg} / \mathrm{dl}$ with mean \pm SD $15.80 \pm 8,572$. Analysis using the Spearman-Rho correlation test obtained p-value $<0.001$ with an R-value of 0.604 . CRP and COVID19 severity were assessed as having statistically significant results.

TABLE 2: Analysis of the Relationship between IL-6 and the Severity of COVID-19

\begin{tabular}{|c|c|c|c|c|c|}
\hline Severity & N (\%) & $\begin{array}{c}\text { Median (Range) } \\
(\mathrm{pg} / \mathrm{ml})\end{array}$ & Mean \pm SD & $\mathbf{p}$ & $\mathbf{r}$ \\
\hline Mild & $6(12 \%)$ & $\begin{array}{c}63,30 \\
(2,71-151,90)\end{array}$ & $69,910 \pm 70,359$ & \multirow{4}{*}{0,017} & \multirow{4}{*}{0,337} \\
\hline Moderate & $6(12 \%)$ & $\begin{array}{c}59,94 \\
(0,24-2197,82) \\
\end{array}$ & $405,950 \pm 878,805$ & & \\
\hline Severe & $25(50 \%)$ & $\begin{array}{c}23,91 \\
(0,62-912,56)\end{array}$ & $88,653 \pm 206,369$ & & \\
\hline Critical & $13(26 \%)$ & $\begin{array}{c}112,38 \\
(45,64-3029,17)\end{array}$ & $455,225 \pm 842,371$ & & \\
\hline
\end{tabular}

*Analysis using Spearman Rho test, statistically significant if $p<0,05$

On the one hand, the results of the examination of IL-6 levels at mild severity had a median (range) of 63.3(2.71 $151.90) \mathrm{pg} / \mathrm{ml}$ with a mean \pm SD $69.910 \pm 70.359$, moderate severity $59.94(0,24-2197.82) \mathrm{pg} / \mathrm{ml}$ with mean \pm SD $405,950 \pm 878,805$, severe severity 23.91(0.62 912.56) $\mathrm{pg} / \mathrm{ml}$ with mean \pm SD $88.653 \pm 206.369$, critical severity 112.38 (45.64 - 3029.17) $\mathrm{pg} / \mathrm{ml}$ with mean \pm SD $455.225 \pm$ 842.371. Analysis using the Spearman-Rho correlation test obtained $p$ value $<0.017$ with an $r$ value of 0.337 . IL- 6 and COVID-19 severity were assessed as having statistically significant results.

TABLE 3: Analysis of the Relationship of CRP with Mortality*

\begin{tabular}{|c|c|c|c|c|}
\hline Mortality & N (\%) & Median (Range) (mg/dl) & Mean \pm SD & p \\
\cline { 1 - 4 } Dead & $15(30 \%)$ & $14,7(2,1-28,8)$ & $14,593 \pm 9,168$ & \multirow{2}{*}{0,004} \\
\cline { 1 - 4 } Life & $35(70 \%)$ & $4,5(0,1-26,3)$ & $6,26 \pm 6,071$ & \\
\hline
\end{tabular}

${ }^{*}$ Analysis using Mann Whitney test, statistically significant if $p<0,05$

Meanwhile, the CRP value in patients who died had a median (range) of $14.7(2.1-28.8) \mathrm{mg} / \mathrm{dl}$ with a mean \pm SD of $14.593 \pm 9.168$, while in living patients it was $4.5(0.1)$. $26.3) \mathrm{mg} / \mathrm{dl}$ with mean \pm SD $6.26 \pm 6.071$.
Analysis using the Mann Whitney comparison test obtained $p$ value of 0.004 . CRP and mortality severity were assessed as having statistically significant results.

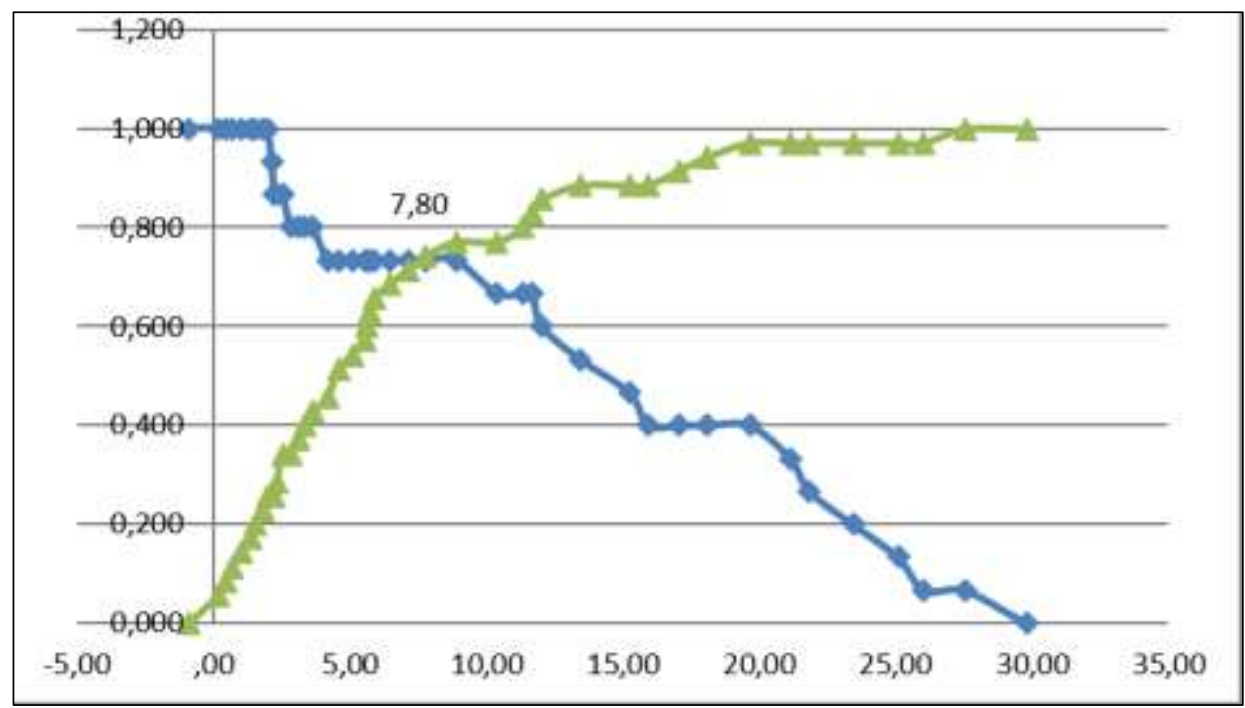

FIGURE 1: Cut off point of CRP on mortality. CRP more than 7,8 mg/dl were associated with mortality.

Based on the results of the correlation between CRP and mortality, then further analysis was carried out using the ROC graph to determine the cut off of CRP on mortality.
Based on the ROC graph, obtained a value of 7.8 as the cutoff point of the CRP value on mortality. Patients with a CRP $>7.8 \mathrm{mg} / \mathrm{dl}$ were associated with mortality. 
TABLE 4: Analysis of the Relationship of IL-6 with Mortality*

\begin{tabular}{|c|c|c|c|c|}
\hline Mortality & N (\%) & Median (Range) $(\mathbf{p g} / \mathbf{m l})$ & Mean \pm SD & p \\
\cline { 1 - 5 } Dead & $15(30 \%)$ & $87,62(3,0-3029,17)$ & $275,512 \pm 764,346$ & \multirow{2}{*}{0,197} \\
\cline { 1 - 4 } Life & $35(70 \%)$ & $36,17(0,24-2197,82)$ & $195,906 \pm 442,950$ & \\
\hline
\end{tabular}

*Analysis using Mann Whitney test, statistically significant if $\mathrm{p}<0,05$

The median (range) of IL- 6 in patients who died was $87.62(3.0-3029.17) \mathrm{pg} / \mathrm{ml}$ with a mean \pm SD of $275.512 \pm$ 764.346, while in patients who lived it was 36.17 (0.24 $2197,82) \mathrm{pg} / \mathrm{ml}$ with mean \pm SD 195,906 $\pm 442,950$.
Analysis using the Mann Whitney comparison test obtained a $p$ value of 0.197 . IL- 6 and mortality were statistically assessed as having no significant results.

TABLE 5: Confounding variables of IL-6*

\begin{tabular}{|c|c|c|c|c|}
\hline Variable & $\begin{array}{c}\text { Frequency } \\
N(\%)\end{array}$ & $\begin{array}{c}\text { Median } \\
\text { (Range })(\mathrm{pg} / \mathrm{ml})\end{array}$ & Mean \pm SD & $\mathbf{p}$ \\
\hline $\begin{array}{l}\text { Sex } \\
\text { Men } \\
\text { Women }\end{array}$ & $\begin{array}{l}34(68 \%) \\
16(32 \%)\end{array}$ & $\begin{array}{c}55,521 \\
(0,62-3029,17) \\
31,976 \\
(0,24-557,61)\end{array}$ & $\begin{array}{r}288,648 \pm 654,535 \\
73,461 \pm 135,435\end{array}$ & $0,167^{*}$ \\
\hline $\begin{array}{l}\text { Age Category } \\
<50 \text { years } \\
\geq 50 \text { years }\end{array}$ & $\begin{array}{l}21(42 \%) \\
29(58 \%)\end{array}$ & $\begin{array}{c}87,622 \\
(0,24-2197,82) \\
40,701 \\
(0,62-3029,17)\end{array}$ & $\begin{array}{l}215,825 \pm 482,045 \\
222,659 \pm 605,592\end{array}$ & $0,461^{*}$ \\
\hline Age Value & $50(100 \%)$ & & & $0,553^{* *}$ \\
\hline $\begin{array}{l}\text { Comorbid } \\
\text { There is } \\
\text { Nothing }\end{array}$ & $\begin{array}{l}37(74 \%) \\
13(26 \%)\end{array}$ & $\begin{array}{c}45,643 \\
(0,62-3029,17) \\
52,954 \\
(0,24-2197,82)\end{array}$ & $\begin{array}{l}205,425 \pm 541,573 \\
260,669 \pm 600,586\end{array}$ & $0,550^{*}$ \\
\hline $\begin{array}{l}\text { BMI Category }\left(\mathbf{k g} / \mathbf{m}^{2}\right) \\
\text { Normal }(18,5-24,9) \\
\text { Overweight }(25-29,9) \\
\text { Obesity }(\geq 30)\end{array}$ & $\begin{array}{l}26(52 \%) \\
16(32 \%) \\
8(16 \%)\end{array}$ & & & $0,100^{* * *}$ \\
\hline $\begin{array}{l}\text { History of Fever } \\
\text { There is } \\
\text { Nothing }\end{array}$ & $\begin{array}{l}39(78 \%) \\
11(22 \%)\end{array}$ & $\begin{array}{c}45,643 \\
(0,24-3029,17) \\
94,521 \\
(1,83-912,56)\end{array}$ & $\begin{array}{l}241,275 \pm 610,424 \\
143,609 \pm 259,880\end{array}$ & $0,665^{*}$ \\
\hline $\begin{array}{l}\text { Secondary Infection } \\
\text { There is } \\
\text { Nothing }\end{array}$ & $\begin{array}{l}20(40 \%) \\
30(60 \%)\end{array}$ & $\begin{array}{c}84,60 \\
(2,03-1254,69) \\
24,776 \\
(0,24-3029,17)\end{array}$ & $\begin{array}{l}141,044 \pm 269,274 \\
272,285 \pm 678,038\end{array}$ & $0,122^{*}$ \\
\hline Length of Hospitalization & $50(100 \%)$ & & & $0,689^{* *}$ \\
\hline
\end{tabular}

${ }^{*}$ Mann Whitney test, statistically significant if $p<0,05$;

${ }^{* *}$ Spearman-Rho test, statistically significant if $p<0,05$;

${ }^{* * *}$ Kruskal test, statistically significant if $p<0,05$. 
Then, from the analysis of the confounding variables, there was no variable with $p$ value $<0.05$ (significant), so it can be concluded that there was no confounding variable that affected IL-6.
On the one hand, it is known that the relationship between CRP and IL- 6 values analyzed using the Spearman-Rho correlation test was found to have $\mathrm{p}<0.001$ with an $\mathrm{r}$ value of 0.557. The correlation between CRP and IL-6 was statistically significant.

TABLE 6: Relationship between CRP and IL-6 with Initial SOFA Score

\begin{tabular}{|l|c|c|}
\cline { 2 - 3 } \multicolumn{1}{c|}{} & $\mathbf{p}$ & $\mathbf{r}$ \\
\hline CRP-SOFA initial score & $<0,001$ & 0,551 \\
\hline IL-6-SOFA initial score & 0,057 & 0,271 \\
\hline
\end{tabular}

In addition, an analysis of the relationship between CRP and IL- 6 values was also carried out with the SOFA score at the time of the initial patient assessment. This analysis was carried out by using the Spearman-Rho correlation test. The $p$ value was $<0.001$ with an $r$ value of 0.551 for the relationship between CRP and the initial SOFA score, and a palue of 0.057 with an $r$ value of 0.271 for the relationship between IL-6 and SOFA initial score. The correlation between CRP and initial SOFA score was statistically significant, while the correlation between IL-6 and initial SOFA score was statistically not significant.

TABLE 7: Analysis of the relationship between CRP and IL-6 with symptom onset*

\begin{tabular}{|l|c|c|}
\cline { 2 - 3 } \multicolumn{1}{c|}{} & $\mathbf{p}$ & $\mathbf{r}$ \\
\hline CRP on symptom onset & 0,224 & 0,175 \\
\hline IL-6 on symptom onset & 0,027 & 0,314 \\
\hline
\end{tabular}

*Analysis using Spearman-Rho test, statistically significant if $\mathrm{p}<0,05$

The relationship between CRP and IL- 6 with the duration of symptom onset was also carried out, using the Spearman-Rho correlation test and obtained a p-value of 0.224 with an R-value of 0.175 for the relationship of CRP to symptom onset, and a p-value of 0.027 with an R-value of 0.314 for the relationship of IL- 6 to the onset of symptoms. The correlation between IL-6 and symptom onset was statistically significant, whereas the correlation between CRP and symptom onset was not statistically significant.

TABLE 8: Correlation of CRP and the use of mechanical ventilation*

\begin{tabular}{|c|c|c|c|c|}
\hline $\begin{array}{c}\text { Mechanical } \\
\text { Ventilation }\end{array}$ & N (\%) & Median (Range) $(\mathbf{m g} / \mathbf{d l})$ & Mean \pm SD & p \\
\cline { 1 - 4 } Yes & $16(32 \%)$ & $11,9(2,1-28,8)$ & $12,743 \pm 8,479$ & \multirow{2}{*}{0,013} \\
\cline { 1 - 4 } No & $34(68 \%)$ & $4,5(0,1-26,3)$ & $6,885 \pm 7,193$ & \\
\hline
\end{tabular}

*Analysis using Mann Whitney test, statistically significant if $p<0,05$

Then, through research it was also known that the median value (range) of CRP in patients using mechanical ventilation during the treatment period was 11.9 (2.1 $28.8 \mathrm{gg} / \mathrm{dl}$ with a mean \pm SD of $12.743 \pm 8.479$, while in patients who never used mechanical ventilation during treatment was $4.5(0.1-26.3) \mathrm{mg} / \mathrm{dl}$ with mean \pm SD 6.885 \pm 7.193 . Analysis using the Mann Whitney comparison test obtained $p$ value of 0.013 . The correlation between CRP and mechanical ventilation treatment was statistically significant.

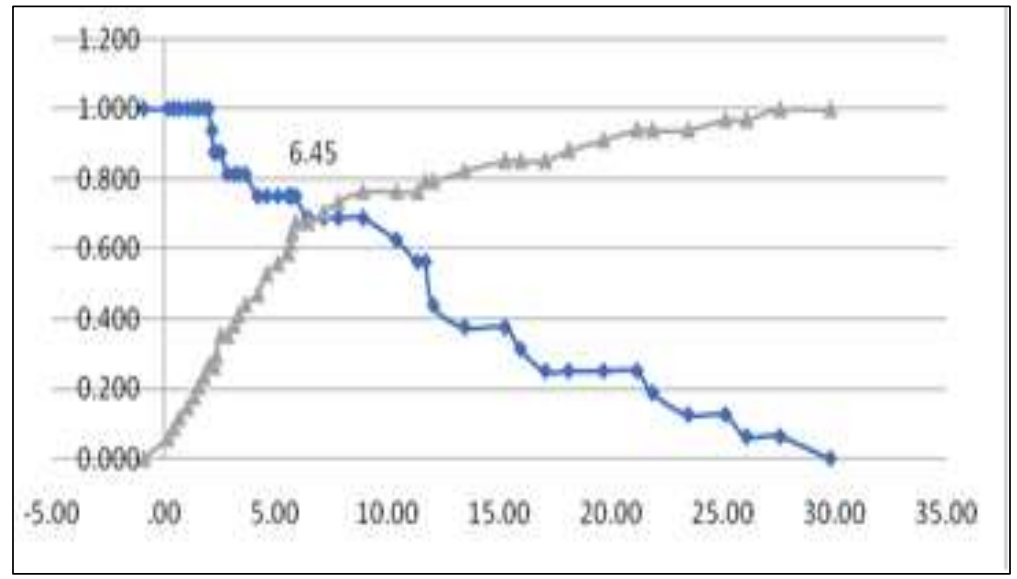

FIGURE 2: Cut off point of CRP and the use of mechanical ventilation.

CRP more than $6,45 \mathrm{mg} / \mathrm{dl}$ were associated with the use of mechanical ventilation during treatment. 
Based on the results of the correlation between CRP and the use of mechanical ventilation, further analysis was carried out using the ROC chart to determine the cut off between CRP and the use of mechanical ventilation.
Based on the ROC graph, a value of 6.45 was obtained as the cut-off point for the CRP value against the use of mechanical ventilation. Patients with CRP $>6.45 \mathrm{mg} / \mathrm{dl}$ were associated with the use of mechanical ventilation during the treatment period.

TABLE 9: Analysis IL-6 with Use of Mechanical Ventilation*

\begin{tabular}{|c|c|c|c|c|}
\hline Mechanical Ventilation & N (\%) & Median (Range) $(\mathbf{p g} / \mathbf{m l )}$ & Mean \pm SD & p \\
\cline { 1 - 5 } Yes & $16(32 \%)$ & $89,494(3,0-3029,17)$ & $367,518 \pm 776,014$ & \multirow{2}{*}{0,027} \\
\cline { 1 - 5 } No & $34(68 \%)$ & $26,654(0,24-2197,82)$ & $150,268 \pm 403,401$ & \\
\hline
\end{tabular}

${ }^{*}$ Analysis using Mann Whitney test, statistically significant if $p<0,05$

The median value (range) of IL-6 in patients using mechanical ventilation during the treatment period was $89.494(3.0-3029.17) \mathrm{pg} / \mathrm{ml}$ with a mean \pm SD $367.518 \pm$ 776.014 , whereas in patients who never used mechanical ventilation during treatment was $26.564(0.24$ - 2197.82) $\mathrm{pg} / \mathrm{ml}$ with mean \pm SD $150.268 \pm 403.401$. Analysis using the Mann Whitney comparison test obtained a p value of 0.027 . The correlation between IL- 6 and mechanical ventilation treatment was statistically significant.

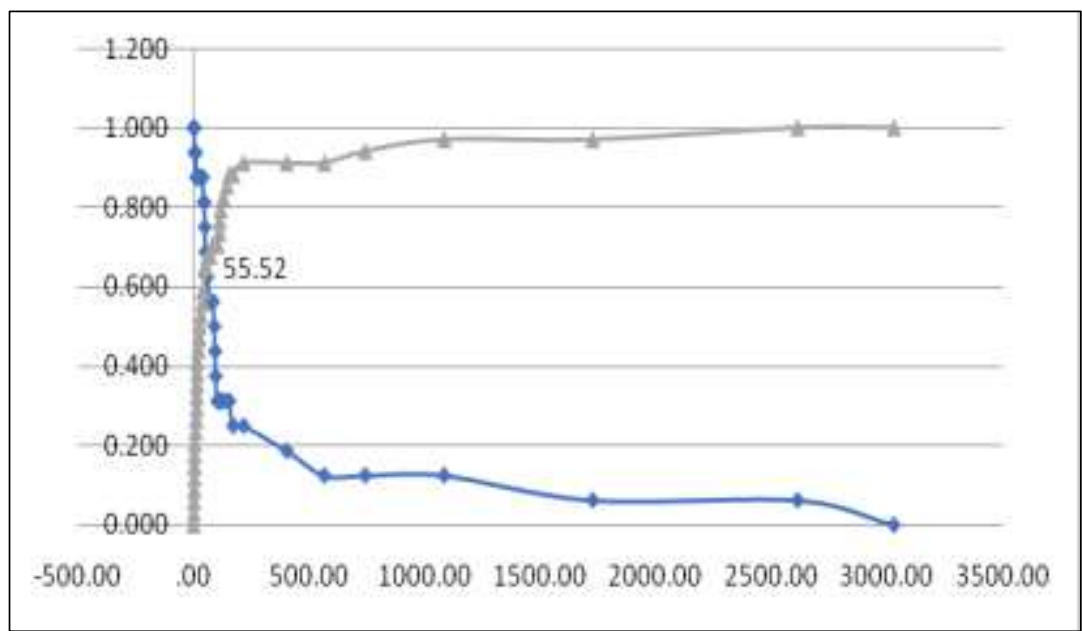

FIGURE 3: Cut off point of IL- 6 and the use of mechanical ventilation.

IL-6 more than $55,52 \mathrm{pg} / \mathrm{ml}$ were associated with the use of mechanical ventilation during treatment.

Based on the results obtained by the correlation between IL- 6 and the use of mechanical ventilation, further analysis was carried out using the ROC chart to determine the cut off between IL- 6 and the use of mechanical ventilation.
Based on the ROC graph, the value of 55.52 was obtained as the cut-off point for the IL- 6 value against the use of mechanical ventilation. Patients with IL-6 results $>55.52$ $\mathrm{pg} / \mathrm{ml}$ were associated with the use of mechanical ventilation during the treatment period.

TABLE 10: correlation between CRP and worsening conditions*

\begin{tabular}{|c|c|c|c|c|}
\hline Worsening condition & N (\%) & Median (Range) $(\mathbf{m g} / \mathbf{d l})$ & Mean \pm SD & p \\
\hline Yes & $33(66 \%)$ & $7,4(0,8-28,8)$ & $10,227 \pm 8,193$ & \multirow{2}{*}{0,041} \\
\hline No & $17(34 \%)$ & $3,9(0,1-26,3)$ & $5,911 \pm 7,080$ & \\
\hline
\end{tabular}

*Analysis using Mann Whitney test, statistically significant if $p<0,05$

Analysis of the CRP value for patients who experienced worsening of the condition during the treatment period, the median value (range) of CRP was $7.4(0.8-28.8) \mathrm{mg} / \mathrm{ml}$ with a mean \pm SD of $10.227 \pm 8.193$ and in patients who had never experienced a worsening of the condition. during the treatment period was $3.9(0.1-26.3) \mathrm{mg} / \mathrm{dl}$ with mean \pm SD $5.911 \pm 7.080$. The analysis was carried out with the Mann Whitney comparison test, the $\mathrm{p}$ value was 0.041 . The correlation between CRP and worsening condition was statistically significant. 


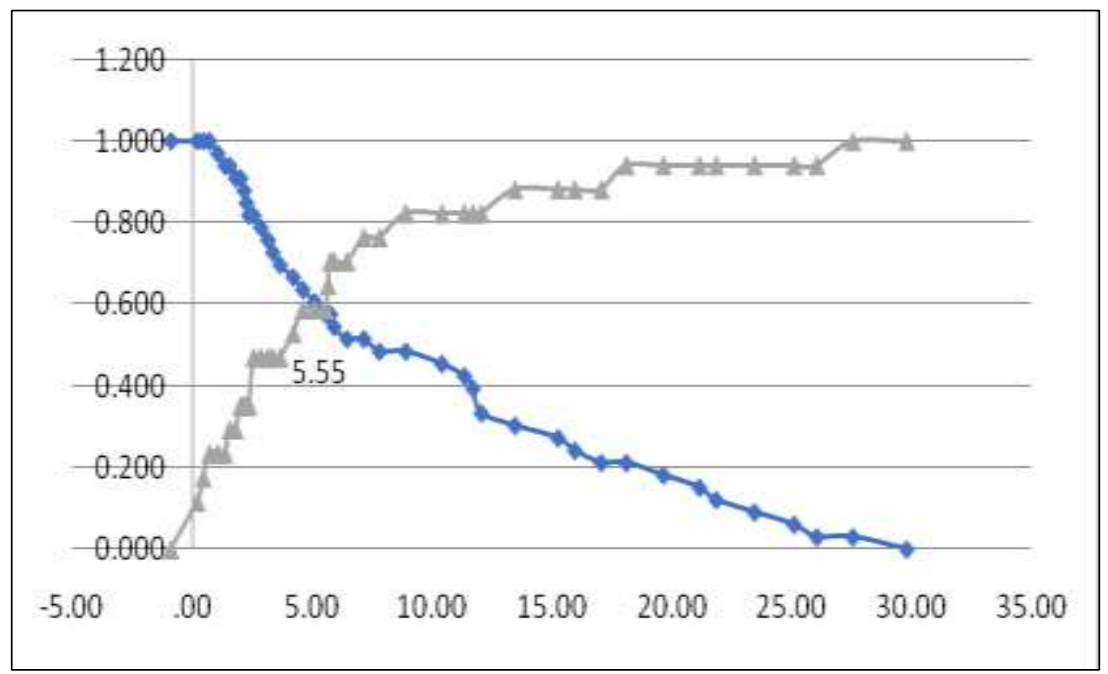

FIGURE 4: Cut off point of CRP and worsening condition during treatment.

CRP more than $5,55 \mathrm{mg} / \mathrm{dl}$ were associated with worsening of the condition during the treatment period.

Based on the results of the correlation between CRP and worsening conditions during the treatment period, further analysis was carried out using ROC charts to determine the cut off between CRP and worsening conditions.
Based on the ROC graph, the value of 5.55 is obtained as the cut-off point for the CRP value to the occurrence of worsening conditions. Patients with CRP results $>5.55$ $\mathrm{mg} / \mathrm{dl}$ were associated with worsening of the condition during the treatment period.

TABLE 11: Analysis of IL-6 with worsening of the condition.

\begin{tabular}{|c|c|c|c|c|}
\hline $\begin{array}{c}\text { Worsening } \\
\text { condition }\end{array}$ & N (\%) & Median (Range) $(\mathbf{p g} / \mathbf{m l})$ & Mean \pm SD & p \\
\cline { 1 - 4 } Yes & $33(66 \%)$ & $48,732(0,62-3029,17)$ & $264,871 \pm 656,063$ & \multirow{2}{*}{0,559} \\
\cline { 1 - 4 } No & $17(34 \%)$ & $23,911(0,24-912,56)$ & $132,274 \pm 243,153$ & \\
\hline
\end{tabular}

*Analysis using Mann Whitney test, statistically significant if $p<0,05$

Analysis of the IL- 6 value for patients who experienced worsening of the condition during the treatment period, the median value (range) of IL-6 was 48,732(0.62 $3029,17) \mathrm{pg} / \mathrm{ml}$ with a mean \pm SD $264.871 \pm 656.063$ and in patients who had never experienced worsening of the condition during the treatment period was 23.911(0.24 912.56) $\mathrm{pg} / \mathrm{ml}$ with mean \pm SD $132.274 \pm 243.153$. The analysis was carried out using the Mann Whitney comparison test, the $\mathrm{p}$ value was 0.559 . The correlation between IL-6 and worsening of the condition was statistically not significant.

\section{DISCUSSION}

This study involved 54 research subjects with the research time being from July to October 2020. Of the 54 research subjects who had met the inclusion and exclusion criteria, there were 4 subjects who dropped out due to incomplete initial data and sample lysis, so that the remaining 50 research subjects were followed in this study until the research was completed. The number of male patients was $34(68 \%)$ and 16 female patients (32\%).

Patients were categorized according to the severity of the China National Health Commission into mild, moderate, severe and critical, with a composition of mild grade as many as 6 patients (12\%), moderate grade 6 patients $(12 \%)$, severe grade 25 patients $(50 \%)$, and critically as many as 13 patients (26\%). On average, patients came with SOFA scores, mean \pm SD $3.24 \pm 1.93$ and median (range) $3.5(0-8)$.

All of these 50 patients had various comorbidities, on average having more than 1 comorbid. There were 17 patients with hypertension (34\%), 14 people with diabetes mellitus (28\%), 8 people with obesity (16\%), asthma and coronary heart disease each 2 (4\%), the rest were COPD, CVA, chronic hepatitis B, reactive HBsAg each as many as 1 person (2\%).

Clinical symptoms that appear vary, the average patient complains of more than 1 clinical symptom, with symptom onset occurring in the range of 1 day to 15 days with a mean \pm SD of $7.4 \pm 3.75$. The most clinical symptoms were fever as many as 37 people (74\%), shortness of breath 37 people (74\%), dry cough 33 people (66\%), runny nose 10 people (20\%), nausea and vomiting 9 people (18\%), decreased appetite eat 8 people (16\%), cough with phlegm 6 people $(12 \%)$, anosmia 6 people $(12 \%)$, diarrhea 5 people $(10 \%)$, sore throat 5 people $(10 \%)$, fatigue 4 people $(8 \%)$, abdominal pain in 3 people $(6 \%)$, myalgia in 2 people $(4 \%)$, chest pain in 2 people (4\%), loss of sense of taste in 1 person (2\%), headache in 1 person (2\%), loss of consciousness in 1 person (2\%), and hemiparesis in 1 person $(2 \%)$.

The onset of symptoms had a median (range) of $7(1-15)$ days with a mean \pm SD of $7.4 \pm 3.75$. During treatment observation, the length of stay had a median(range) of $18(2-69)$ days with a mean \pm SD of $20.7 \pm 14.01$.

The worsening of the condition was assessed based on vital signs such as heart rate, blood pressure, body temperature, respiratory rate, consciousness, type of oxygen assistance or oxygen supplementation, laboratory results such as routine blood, blood gas analysis, BUN, serum creatinine, bilirubin, use of CRRT, ventilation mechanical, the use of vasoactive drugs such as adrenaline, norepinephrine, dopamine, dobutamine, milrinone, complications such as bacterial secondary infection evidenced by culture results, bleeding and blood clotting 
disorders, and other complications. The number of patients died as many as 15 people (30\%) and 35 people $(70 \%)$ lived based on mortality observations until the 28th day of treatment.

The results of the CRP examination in this study had a median (range) of $5.65(0.10-28.80) \mathrm{mg} / \mathrm{dl}$, with a mean $\pm \mathrm{SD}$ of $8.76 \pm 8.029$. IL-6 examination had a median (range) of $46.712(0.24-3029.17) \mathrm{pg} / \mathrm{ml}$, with a mean \pm SD of $219.788 \pm 551.744$

Analysis of the relationship between CRP and the severity of Covid-19 in this study showed statistically significant results with a $\mathrm{p}$ value of $<0.001$ which was declared significant if the $\mathrm{p}$ value $<0.05$ and had a correlation coefficient or $r$ value of 0.604 where the $r$ value was $>0.5$ can be said to have a strong correlation. The more severe the severity of the patient's COVID-19, the higher the CRP value in the first 24 hours of hospitalization. Statistical analysis using Spearman-Rho correlation test.

Meanwhile, the results of the analysis of the relationship between IL- 6 and the severity of Covid-19 showed the mean \pm SD IL-6 in patients with mild degrees of $69,910 \pm$ 70,359 with a median (range) of 63.3 (2.71 - 151.90) pg/ $\mathrm{ml}$, at moderate degree $405.950 \pm 878.805$ with median(range) $59.94(0,24$ - 2197.82) $\mathrm{pg} / \mathrm{ml}$, severe degree $88.653 \pm 206.369$ with median(range) 23.91(0.62 912.56) $\mathrm{pg} / \mathrm{ml}$, critical degree 455,225 $\pm 842,371$ with median(range) $112,38(45,64$ - 3029,17) pg/ml. This shows a statistically significant result with a p value of $<$ 0.017 which is stated to be significant if the $p$ value $<0.05$ and has a correlation coefficient or $r$ value of 0.337 where in this case the value of $r<0.5$ can be said to have a weak correlation. The more severe the severity of the patient's COVID-19, the higher the IL- 6 value in the first 24 hours of hospitalization. The standard deviation value for the IL- 6 value was very large because there were 3 patients with an IL- 6 value above $1000 \mathrm{pg} / \mathrm{ml}$ where 1 of them had an IL-6 above $3000 \mathrm{pg} / \mathrm{ml}$. Statistical analysis using SpearmanRho correlation test.

IL-6 levels were significantly increased when the patient was admitted to the hospital in severe cases compared to non-severe cases (9). It was also stated in another study that IL-6 levels were $25.2 \mathrm{pg} / \mathrm{ml}$ in severe cases compared to $13.3 \mathrm{pg} / \mathrm{ml}$ in non-severe cases with $\mathrm{p}<0.001$ (10). A systematic review by Russell et al, said that the blood level of IL-6 with the optimum critical point value of $24.3 \mathrm{pg} / \mathrm{ml}$ in more severe cases where this value is the upper limit value for severe pneumonia (11).

It is known that there were 15 patients who died from a total of 50 patients who participated in this study (30\%), of the 15 patients who died had a mean \pm SD CRP of 14,593 \pm 9.168 with a median (range) of $14.7(2.1-28,8) \mathrm{mg} / \mathrm{dl}$, while in living patients the mean \pm SD was $6.26 \pm 6.071$ with a median (range) of $4.5(0.1-26.3) \mathrm{mg} / \mathrm{dl}$. Using the statistical analysis of the Mann Whitney comparison test because the data was not normally distributed, it was found that the $p$ value was 0.004 where the $p$ value $<0.05$ was statistically significant. Then, the cut off value of CRP on mortality was 7.8 with units of $\mathrm{mg} / \mathrm{dl}$.

CRP is a nonspecific acute phase protein induced by IL- 6 in the liver and is a sensitive biomarker of inflammation, infection and tissue damage. CRP levels are usually low, but increase rapidly and markedly during the acute inflammatory response. An increase in CRP alone or in combination with other markers indicates a bacterial or viral infection (12).
Then, the analysis of the relationship between IL- 6 and mortality showed a mean value of $275.512 \pm 764,346$ with a median value (range) of 87.62 (3.0 - 3029.17) pg/ml of 15 people and a mean \pm SD of $195.906 \pm 442.950$ with a median value (range) of 36.17 (0.24 - 2197.82) pg/ml as many as 35 people. Through the median and mean values of IL-6 on mortality, it was seen that IL-6 levels were higher in patients who died.

This analysis resulted in a p value of 0.197 where the $p$ value $<0.05$ was said to be significant. The analysis used the Mann Whitney comparison test because the data were not normally distributed. Statistically the number of IL-6 levels has no relationship with the occurrence of mortality, this is because the data has a standard deviation that is too large.

Based on these results, a confounding variable analysis test was conducted on IL- 6 . The analysis test included gender variables, age categories $<50$ years and 50 years, age values with a range of 25-76 years, presence or absence of comorbidities, BMI categories (normal, overweight and obese), presence or absence of a history of fever, presence or absence of secondary bacterial infection during treatment, and length of hospitalization. The results did not show that there was a confounding variable for IL-6 because all $p$ values were $>0.05$ (11). This may be related to the function and role of IL- 6 in the classical pathway as an anti-inflammatory and the trans pathway as proinflammatory, where in COVID-19 mainly the role of the IL6 trans pathway (4). However, there is no literature that can explain the role of the classical IL-6 pathway that provides anti-inflammatory effects in COVID-19.

Meanwhile, the analysis of the relationship between CRP and IL-6 using the Spearman-Rho correlation test because the data is not normally distributed, the $\mathrm{p}$ value $<0.001$ is obtained where the p value $<0.05$ is said to be statistically significant. The value of $r$ is 0.557 which can be said if the value of $r>0.5$ then it has a fairly strong correlation. This indicates that IL6 and CRP have a strong correlation, and an increase in IL- 6 is usually followed by an increase in CRP.

Effects on hepatocytes, IL-6 is a potent trigger of acute phase reactive protein, which can trigger hepatocytes to synthesize acute phase reactive proteins at the gene transcription level, especially serum amyloid A (SAA) and C-reactive protein (4). Significantly there is a relationship between increased levels of IL-6 with increased levels of CRP, ferritin, and D-dimmer (9).

Then, the analysis of CRP with SOFA scores was carried out using the Spearman-Rho correlation test, it was found that there was a relationship between CRP and SOFA scores that were assessed in the first 24 hours of treatment with $p$ value $<0.001$ where $p<0.05$ was statistically significant and $r$ value of 0.551 . This shows that CRP with SOFA score has a fairly strong correlation, where the CRP value will be higher in patients who have a higher SOFA score.

Analysis of IL-6 with SOFA scores was also carried out using the Spearman-Rho correlation test, obtained $p$ value of 0.057 where $p<0.05$ was statistically significant with $r$ value of 0.271 . This shows that there is no relationship between IL-6 and SOFA scores.

On the other hand, the relationship between CRP and symptom onset was carried out using the Mann Whitney comparison test, it was found that the $\mathrm{p}$ value was 0.224 where $\mathrm{p}<0.05$ was statistically significant, with an $\mathrm{r}$ value of 0.175 . 
This shows that there is no relationship between the duration of symptom onset and CRP.

It is known that there were 16 people (32\%) who used mechanical ventilation during treatment out of a total of 50 patients in this study. Of the 16 patients using mechanical ventilation there were 8 patients who were intubated and mechanically ventilated in the first 24 hours of treatment, 8 other patients started using mechanical ventilation between the second day of treatment until the 10th day of treatment.

Based on this, an analysis test was performed using the ROC chart and the cut off value was 6.45 . This shows that a CRP value $>6.45 \mathrm{mg} / \mathrm{dl}$ is associated with patients who are mechanically ventilated during their treatment, while a CRP $<6.45 \mathrm{mg} / \mathrm{dl}$ is associated with patients who have never used mechanical ventilation.

This study also showed a CRP cut off value which was much lower than previous studies, where CRP cut off levels $>97$ $\mathrm{mg} / \mathrm{L}$ had a risk of respiratory failure, thus IL- 6 and CRP were predictive factors for the need for mechanical ventilation in COVID patients. -19 (13).

The mean \pm SD IL 6 was $367,518 \pm 776,014$ in patients who used mechanical ventilation during treatment and 150,268 $\pm 403,401$ in patients who never used mechanical ventilation during treatment with a p value of 0.027 where $\mathrm{p}<0.05$ was statistically significant. The analysis uses the Mann Whitney comparison test. This shows that the number of IL-6 levels in patients has a relationship with the use of mechanical ventilation during treatment, where the mean \pm SD IL- 6 value in patients who use mechanical ventilation is higher than those who have never used mechanical ventilation during treatment.

Based on this, an analysis was carried out using the ROC chart and obtained a value of 55.52 as the cut off value of IL-6 for the use of mechanical ventilation during treatment. This suggests that patients with IL-6 levels > $55.52 \mathrm{pg} / \mathrm{ml}$ were associated with the use of mechanical ventilation during treatment and IL-6 levels $<55.52 \mathrm{pg} / \mathrm{ml}$ were associated with patients who never used mechanical ventilation during treatment.

Increased IL-6 correlates with administration of glucocorticoids, human immunoglobulins, high-flow oxygen and use of mechanical ventilation during hospitalization (9). IL-6 levels $>80 \mathrm{pg} / \mathrm{mL}$ have a risk of respiratory failure, thus IL- 6 and CRP are predictive factors for the need for mechanical ventilation in COVID-19 patients (13). The findings on the results of the study have a cut off value that is much lower than previous studies.

It is known that there were 33 patients (66\%) who experienced worsening during treatment, while the rest did not experience worsening, of these 33 patients the worsening of the condition occurred between day 4 to day 22 of treatment calculated from the onset of symptoms. The relationship between CRP values and the occurrence of worsening conditions during the treatment period was carried out using the Mann Whitney comparison test and obtained a mean \pm SD CRP value of $10.227 \pm 8.193$ in patients who experienced worsening during the treatment period and $5.911 \pm 7.080$ in patients who during the treatment period never experienced worsening of the condition. A p value of 0.041 was obtained where $p<0.05$ was statistically significant. This shows that there is a relationship between CRP levels and the occurrence of worsening conditions during the treatment period where the greater the CRP value is associated with the occurrence of worsening conditions.
Analysis with the ROC graph was carried out for the CRP value for the occurrence of worsening conditions and the cut off value was 5.55. This shows that patients with CRP values $>5.55 \mathrm{mg} / \mathrm{dl}$ were associated with worsening during the same treatment and patients with CRP values < $5.55 \mathrm{mg} / \mathrm{dl}$ were associated with patients who never had worsening conditions.

The mean \pm SD IL- 6 was found to be $264.871 \pm 656.063$ in patients who experienced worsening of the condition during the treatment period and $132.274 \pm 243.153$ in patients who never experienced worsening of the condition during the treatment period. The $\mathrm{p}$ value of 0.559 was obtained where $\mathrm{p}<0.05$ was statistically significant. The analysis was carried out using the Mann Whitney comparison test. This shows that there is no correlation between IL- 6 values and the occurrence of worsening conditions during the treatment period.

IL-6 levels in 30 patients who were examined before and after therapy showed 26 patients had a decrease in IL-6 levels after therapy, this was followed by an improvement in the patient's condition, but in 4 other patients there was a persistent increase in IL-6 followed by worsening of the condition. in that patient (9).

\section{CONCLUSION}

From this study it can be concluded that examination of CRP and IL-6 was associated with severity, complications and mortality in COVID-19 patients, except that IL-6 was not associated with mortality because it is influenced by the patient's comorbid disease.

\section{REFERENCES}

[1] Rothan HA, Byrareddy SN. The epidemiology and pathogenesis of coronavirus disease ( COVID-19) outbreak. J Autoimmun. 2020;xxx(xxxx):1-4.

[2] Rodriguez-Morales AJ, Cardona-Ospina JA, GutiérrezOcampo E, Villamizar-Peña R, Holguin-Rivera Y, Escalera-Antezana JP, et al. Clinical, laboratory and imaging features of COVID-19: A systematic review and meta-analysis. Travel Med Infect disesase. 2020;xxx(xxxx):1-14.

[3] Ruan Q, Yang K, Wang W, Jiang L, Song J. Clinical predictors of mortality due to COVID - 19 based on an analysis of data of 150 patients from Wuhan , China. Intensive Care Med. 2020;1-3.

[4] Magro G. SARS-CoV-2 and COVID-19: Is interleukin6 ( IL-6) the 'culprit lesion' of ARDS onset? What is there besides Tocilizumab? SGP130Fc. Cytokine. 2020;X 2(100029):1-7.

[5] Sproston NR, Ashworth JJ. Role of C-Reactive Protein at Sites of inflammation and infection. Front Immunol. 2018;9(754):1-11.

[6] Liu F, Li L, Xu M Da, Wu J, Luo D, Zhu YS, et al. Prognostic value of interleukin-6, C-reactive protein, and procalcitonin in patients with COVID-19. J Clin Virol. 2020;127(April):104370.

[7] Guillon A, Hiemstra PS, Si-Tahar M. Pulmonary immune responses against SARS - CoV - 2 infection: harmful or not? Intensive Care Med. 2020;8-11.

[8] Vincent JL, Moreno R, Takala J, Willatts S, De Mendonça A, Bruining H, et al. The SOFA (Sepsisrelated Organ Failure Assessment) score to describe organ dysfunction/failure. On behalf of the Working 
Group on Sepsis-Related Problems of the European Society of Intensive Care Medicine. Intensive Care Med. 1996;22(7):707-10.

[9] Liu T, Zhang J, Yang Y, Ma H, Li Z, Zhang J, et al. The potential role of IL- 6 in monitoring severe case of coronavirus disease 2019. preprint. 2020;1-24.

[10] Qin C, Zhou L, Hu Z, Zhang S, Yang S, Tao Y, et al. Dysregulation of immune response in patients with COVID-19 in Wuhan, China Chuan. Infect Dis Soc Am. 2020;1-24.
[11] Russell B, Moss C, George G, Santaolalla A, Cope A, Papa $S$, et al. Associations between immunesuppressive and stimulating drugs and novel COVID19 - a systematic review of current evidence. Ecancermedicalscience. 2020;14(1022):1-43.

[12] Peisajovich A, Marnell L, Mold C, Du Clos TW. Creactive protein at the interface between innate immunity and inflammation. Expert Rev Clin Immunol. 2008;4(3):379-90.

[13] Herold T, Jurinovic V, Arnreich C, Lipworth BJ. Elevated levels of IL- 6 and CRP predict the need for mechanical ventilation in COVID-19. Am Acad Allergy, Asthma Immunol. 2020;(January):128-36. 